\title{
EXTERNALITY ANALYSIS OF COMMUNITY FOREST MANAGEMENT
}

Mahesh Raj Dahal, PhD

Principal of University Campus

T.U., Kirtipur, Kathmandu

\begin{abstract}
This paper attempts to analyze the positive and negative externality effects of community forest management with the help of household level monetary value of benefits and costs derived from the sixteen community forest user groups of households in Arun River Valley. Monetary benefits of major types of forest products and total costs of forest use and management were calculated classifying into labour cost, transaction cost and membership fees to derive monetary estimation for the purpose of externality analysis. With the help of summary statistics of calculated gross benefits and costs including net benefits and the benefit-cost ratios $(B / C)$ the externality effects of use and management of community forest were examined. The results of externality analysis shows that the poor income households are completely failed to internalize the benefit from $C F$ as per the total gross cost per household incurred equivalent by negative net benefits (-4.0 percent). The middle income households are being able to internalize by equalize both of gross benefit (37.0 percent and the total gross cost (37.0 percent) from CF. The rich income households are being able to externalize the total gross cost on the poor income households to gain disproportionate net benefits (4.0) from CF. The benefit-cost ratios $(B / C)$ for the poor $(0.81<1)$, medium $(1=1)$ and rich households $(1.09>1)$ also have justified that the rich households are getting higher percentage of net benefits and paying less percentage of gross cost without providing any compensation to the poor households. The middle income households appeared in a position of no more gain nor more loss or zero net benefit. Since even a benefit loser, the poor households should take part in overall total gross cost of forest use, operation and management. Thus, the net externality effect of CF in terms of benefits accrued (positive externality) minus total gross cost incurred (negative externality) i.e. net benefit is negatively related to the poor income households and positively related to richer households in the study area.
\end{abstract}

Kew words: Community forest management, externality, opportunity cost, benefit-cost analysis

\section{INTRODUCTION}

Externalities refer to the effects of benefits and costs of forest resource management activities not directly reflected in the market. An externality occurs when one person's consumption or production behavior affects that of another without any compensation. A community forest (CF) refers to common property resources that benefits all users who are authorized members of forest user group (FUG). The price of the forest goods need not reflect its social value in consumption and management due to presence of externalities. Therefore, some households may use or consume too much and some households may use or consume too little so that equity outcome of forests may be inefficient. The possible remedies involve legal rights of those adversely affected to charge and provision of alternative incentives such as availability of electricity and gas at discount rate to those who create negative externalities.

Externalities can be negative or positive. Negative externality occurs in the community forests when any one uses or consumes too little CF goods by sharing high common management costs than the other one, i.e., one may unable to internalize the positive externality in terms of benefits from $\mathrm{CF}$ as his rivals could do. Similarly, positive externality occurs in the community forests when one uses or consumes too many by imposing common management costs on the other, i.e. one may able to externalize the negative externality in terms of costs from $\mathrm{CF}$ as their rival could not do. The benefits and costs of one's action (use and management of $\mathrm{CF}$ ) are said to be internalized when one is made to bear them in full (Todaro, 2004). Each of the income group of households, however, have no incentive to account for the external costs and benefits that they impose or share to one another when making use and management decisions of community forests as a common property resources. Moreover, there is no market in which these external costs and benefits from the community forests can be transmitted into the price of forest products used by different income groups of forest user households.

The part of externality issues- negative externality in terms of transaction cost and positive externality in terms of benefit from community forest management are taken into account to measure the positive-negative externality effects. The positivenegative externalities have differential impacts of actual benefits accrued and transaction costs incurred by different wealth- ranked groups within the community forest user groups (CFUGs). The 
CPR literature argued that defining property rights internalized the externality. However, despite the defining communal usufruct property rights of community forests of Nepal in place, those nonpoor households are benefiting more than the poor households by imposing the greater transaction costs on the poor households. Unless internalization of positive externality in terms of benefits reaped and negative externality in terms of costs incurred by all different income groups of households within the CFUGs, there is remaining the question about the likelihood of collective action, equity and efficiency issues in the people's participatory communal management of community forests.

This article tries to analyze the externalities of community forest in terms of benefits accrued from and costs incurred of use and management of community forest by the local level forest user households.

\section{MATERIALS AND METHODS}

The materials of this article are based on the author's Ph.D. research study which was undertaken in two selected districts of eastern hilly Arun river valley of Nepal where participatory forest resource management under the user's group concept has been implemented for last twenty years. Altogether sixteen CFUGSs from four VDCsJarayotar, Yaku and Chharambi of Bhojpur district and Leguwa of Dhankuta district- in Arun Valley were selected. A PRA technique was applied to distinguish all the households into three wealthranked groups for realistic assignment of poor and non-poor households based on multidimensional local criteria as adopted by Fox (1983), Richards et al. (1999), Varughese \& Kanel (2000), Bhattarai \& Ojha (2001) and Adhakari (2003).

Compiling a census of all households under the community forest users groups, a stratified sample was chosen for households' survey to get household level data on socio-economic and demographic information and institutional regime of community forest use and management of 400 households out of total 1224 households from 16 CFUGs in four VDCs of two districts. The household sample represented the average of 32 percent of total households from each CFUGs vis-à-vis of each wealth-ranked group of households in a proportional basis of the study area as a whole. One out of 400 questionnaires was removed from the final analysis being due to incomplete.

In addition to primary data, the other necessary data on institutional arrangements with regard to appropriation of forest products and provision rules, collective-choice arrangements and conflicts regulation mechanisms have been complied from various operational plan and written documents \minutes of each CFUGs. Other important information has been used as and when necessary from various publications of $\mathrm{GON} \backslash \mathrm{NPC} \backslash \mathrm{CBS}$ and other research centers and professionals.

To analyze the externalities effects of community forest for different income groups of forest user households, estimation of benefits accrued from and costs incurred of use and management community forest is essential. For this purpose, monetary value of benefits and costs has been derived using appropriate methods formulas.

\section{Calculation of Benefits (Income) from Different Type of Community Forest Products}

To estimate the economic value of different forest products the market price, barter method and opportunity cost approach were used. To estimate the economic value (income) of different forest products the market price, barter method and opportunity cost approach were used. (Gunatilake, 1998); \& (Adhikari, 2003) were also estimated the economic value of fuel wood consumed at home was valued at retail price in the village or forest gate price. This study has also estimated the economic value of fuel wood based on retail market price prevailing in local market. The economic value of fodder, green grass and dry and green leaf litter were valued by the barter game methods. Similar methods were used by Godoy et al., 1993; Richards et al.., 1999; \& Adhikari, 2003 in their studies.

Household level benefits derived from community forest by the local users were calculated by valuing the different forest product collected and harvested from forest areas. Gross economic value of different forest products is calculated by multiplying the quantity of forest products harvested by the price of respective products minus cash cost like direct cash payment to community forest user group (CFUG) as entrance fees for initial membership and if any other monthly membership fees. Hired labour to collect the forest product was completely absent. So cost of such labor has not been considered here. Due to the climate changes, different rule of user groups and seasonal agricultural farming activities, information of the amount of different forest products collected by the local user however, varies with the seasons was collected for 12 successive months. Considering all sites, green fuel wood harvesting was a restricted activity that could 
only be harvested once or twice a year for a fixed period of time. Fuel wood and other forest products could not be harvested for commercial purpose.

In order to carry out the barter game method, the user participants in group discussion were divided into two groups, i.e., buyers and sellers, with buyers purchasing fodder, green grass and dry and green leaf litter in exchange for local goods which had a well-known local market value. In this exercise, buyers were given a bag of maize and the sellers were given a bundle of fixed unit of each (one head load of a bhari) of fodder, green grass and dry and green leaf litter. The participants were asked to discuss within their group about the quantity of maize they deserved in exchange for these different forest products. Finally, they actually exchanged the products for a fixed quantity of maize after a consensus was formed between all members within the group. Thus, the value of one head load tree fodder $=1.2 \mathrm{~kg}$ maize, one head load cut grass $=1.3$ $\mathrm{kg}$ maize, one head load green leaf litter $=1.0 \mathrm{~kg}$ maize, and one head load dry leaf litter $=1.2 \mathrm{~kg}$ maize was derived through such type of barter game exercise since the market value of maize was well established (NRs 15/ kg maize). Thus, All harvested different forest products as mentioned above by users from the community forests are considered as benefits. In other words, gross value/benefits (income) of community forests is defined as total annual gross income received from the forestry activities by the different income groups of forest users households in the study area.

Gross benefit (economic value) of firewood is calculated by multiplying the quantity of firewood (per head load (bhari) by the local market price (Rs.35/ per head load). Gross economic value of tree fodder, cut grass, green and dry leaf litter were calculated by multiplying the quantity of each harvested forest products per head load by the barter game prices- Rs.18 / head load, Rs.20/head load, Rs.14/head load, and Rs.18/head load respectively. Gross economic value of tree branch (teka) was calculated by multiplying the quantity of tree branch (teka) by user's price Rs.18/N. Similarly, Gross economic values of timber for house and animal shed construction were estimated based on local market price. Gross economic values of Sal timber were calculated by multiplying the cubic feet by local market price Rs 500/ cubic feet and non-Sal timber were calculated by multiplying the cubic feet by local market price Rs 150/ cubic feet. Gross economic value of other Sal woods-long pole and Small pole- (balo, garalo, valsi were calculated by multiplying the quantity by local market price Rs 500/N and Rs 300/N respectively. Similarly, gross economic value of other non-Sal woods- long pole and Small pole-(balo, garalo, valsi) were calculated by multiplying the quantity by local market price Rs.200/N and Rs.100/N respectively. Gross economic value of plough was calculated by multiplying the quantity by local market price Rs.50/N. To get the gross total value for each income group, all the items of gross economic value from different forest products are added in each case. The gross total value (benefit) obtained by households were quantified and averaged to represent the gross economic value or benefit per household for each income group of households.

\section{Calculation of Different Cost Structures of Community Forest Management}

Three types of costs-labor cost, transaction cost and cash cost, borne by users were identified for the cost analysis. Labor cost were calculated as labor costs of time directly associated with finding, extracting, processing and transporting the different types of forest products from the forest areas to the house multiplying by the per man day average wage rate at all the study sites. According to the local condition average 7 hours were reported for one-day working hour and average wage rate for one-day were reported as NRs. 50.

Transaction costs- (decision making cost, implementation cost and monitoring cost) simply measured in terms of labour opportunity costs of time spent in decision-making activities, different types of forestry implementing activities and different types of forestry monitoring activities. It was calculated as labour costs of time directly associated with decision-making activities, implementing activities and monitoring activities multiplying by the per man day average wage rate at all the study sites. According to the local condition average 7 hours were reported for oneday working hour and average wage rate for oneday were reported as NRs. 50. A membership fee refers the fees required to pay to become a socially permitted user within the specified CFUG. It is a compulsory fee amount decided by the general assembly of each CFUG to enter into the CFUG. Those users who do not have willingness to pay outright excluded from the forest resource use. To get the total gross cost for each caste and income group, these costs were added in each case. The cost incurred by households were quantified and averaged to represent the cost per household for each caste and income groups.

\section{RESULTS AND DISCUSSIONS}

Based on above materials and methods per household monetary values of management costs 
of community forests for the three income groups has been derived in the following Table 1. rich and medium income groups do. However, this implies that poor income group seems to be active in forest implementation activities rather than

Table 1

Labour Cost, Transaction Costs and Membership Fees per Household by Income Groups

(In Nepalese Rupees)

\begin{tabular}{|c|c|c|c|c|c|c|c|c|}
\hline \multirow{3}{*}{ Income Class } & \multicolumn{6}{|c|}{ Average Costs } & \multirow{2}{*}{\multicolumn{2}{|c|}{$\begin{array}{c}\text { Total Average } \\
\text { Gross Cost }\end{array}$}} \\
\hline & \multicolumn{2}{|c|}{ Labour Cost } & \multicolumn{2}{|c|}{ Transaction Cost } & \multicolumn{2}{|c|}{ Membership Fees } & & \\
\hline & NRs. & $\%$ & NRs. & $\%$ & NRs. & $\%$ & NRs. & $\%$ \\
\hline $\operatorname{Rich}\left(N^{*}=111\right)$ & 3,458 & 69.0 & 1,308 & 26.0 & 250 & 5.0 & 5,017 & 41.0 \\
\hline Middle $\left(\mathrm{N}^{*}=143\right)$ & 3,061 & 68.5 & 1,115 & 25.8 & 253 & 5.7 & 4,469 & 37.0 \\
\hline Poor $\left(\mathrm{N}^{*}=145\right)$ & 1,359 & 50.9 & 1,068 & 40.0 & 243 & 9.1 & 2,669 & 22.0 \\
\hline Average Costs & 2,553 & 64.3 & 1,166 & 29.4 & 249 & 6.3 & 3,967 & 100.0 \\
\hline
\end{tabular}

*Number of Households

Source: Field Survey, 2003.

\section{Monetary Structure of Total Costs}

Table 1 summarizes the labour costs and membership fees of forest use and transaction costs of forestry operation based on surveyed households of three income groups in category.

Table 1 show that average labour cost is two times higher than the average transaction cost of forestry operation and management for all income groups. While average membership fees is less than 1 percent to total cost. The table 1 clearly shows that within the income groups all are appeared bearing a largest fraction of average labour costs (64.3 percent) followed by transaction cost (29.4 percent) and membership fees (6.3 percent) respectively. However, households from the poor income group have bearing relatively higher transaction cost than the households of rich and middle-income groups. It can be said that out of total cost, 31.0 percent for rich income group, 31.5 percent for middle income group and 49.1 percent for poor income group are attributed to transaction costs including membership fees which was forced after community forestry. A very high level of transaction costs to poor income groups compared to rich and middle- income group is an indication of disproportionate shares in implementation activities rather than decision-making and monitoring activities by poor income groups than overall forest management and utilization activities than the rich and medium groups of households. The great variation of share of transaction cost between poor and non-poor households indicates the differences in scale of forest management. However, this difference means that the higher intensity of forest management may not always need higher transaction costs in meetings and decision-making. It may not be true that higher transaction cost leads leadership in meetings implementation and decision-making activities and hence ensures more likely the higher benefit from CF. Thus, the transaction costs including membership fees seems an obligatory cost of common property forest resource management to be remaining a legal and authorized member to use forest resources at subsistence scale from CF by all income groups as this was not a necessity when the forest was de facto an open access prior to management of forest by local community user groups.

\section{Difference between Monetary Value of Gross Benefits and Costs $=$ Net Benefits}

Table 2 shows the household level gross and net value/benefits (income) of CF among the three income groups of forest user households based on surveyed households. 


\section{Table 2}

Per Household Monetary Value of Gross Benefits and Costs and Net Benefit from CF by Income Group

(In Nepalese Rupees)

\begin{tabular}{|l|c|c|c|c|c|c|c|}
\hline Income Groups & $\mathrm{N}^{*}$ & $\begin{array}{c}\text { Gross } \\
\text { Benefit }\end{array}$ & Percent & $\begin{array}{c}\text { Gross } \\
\text { Cost }\end{array}$ & Percent & $\begin{array}{c}\text { Net } \\
\text { Benefit }\end{array}$ & $\begin{array}{c}\text { Percentage } \\
\text { Difference }\end{array}$ \\
\hline Rich & 111 & 7,786 & 45.0 & 5,017 & 41.0 & 2,769 & 4.0 \\
\hline Middle & 143 & 6,397 & 37.0 & 4,469 & 37.0 & 1,928 & 0.0 \\
\hline Poor & 145 & 3,236 & 18.0 & 2,669 & 22.0 & 567 & -4.0 \\
\hline Total and Average & 399 & 5,636 & 100.0 & 3,967 & 100.0 & 1,667 & 100.0 \\
\hline
\end{tabular}

${ }^{*}$ Number of Households

Source: Computed from Annex Tables $A$ and $B$

Above Table shows that compare to gross costs wealthier households are getting higher gross and net value from $\mathrm{CF}$ followed by the middle-income and poor households. Income from CF increases gradually as one moves from the lowest to the highest income group. This may be because poorer households have less land and livestock ownership and they are not use intermediate forest products like fodder, leaf litter and grasses. These findings groups, comparison of net income suggests that the three income groups are statistically different.

\section{Benefit - Cost Ratio (B/C) for Three Income Groups}

Table 3 summarizes the distribution of household level net benefits for three income groups.

Table 3

Percentage Distribution of Net benefits (Income) among Income Groups (In Nepalese Rupees)

\begin{tabular}{|c|c|c|c|c|}
\hline Income Groups(a) & Gross Benefits(b) & Gross Costs $(\mathrm{c})$ & Net Benefits $(\mathrm{d})=\mathrm{b}-\mathrm{c}$ & B/C Ratio (e) $=\mathrm{b} / \oint$ \\
\hline Rich & 45.0 & 41.0 & 4.0 & 1.09 \\
\hline Medium & 37.0 & 37.0 & 0.0 & 1.0 \\
\hline Poor & 18.0 & 22.0 & -4.0 & 0.81 \\
\hline
\end{tabular}

Source: Computed from Annex Tables $A$ and B

are similar to that of (Richards et aI., 1999; \& Adhikari, 2003), which substantiate that poorer households are at present benefiting less from $\mathrm{CF}$ mainly because they have less livestock and farmland, which provide the main demand for forest products as inputs.

The average percentage difference of net benefit (income) per household from CF is presented on the last column of Table 2. Non-poor households are still better off than poorer households from CF. It appears that both the gross income and net income from CPR is an increasing function of wealth and both are significantly different between income
Table 3 shows that poor households have getting relatively less gross value from and sharing more gross cost to $\mathrm{CF}$ and hence have negative benefit to them contrary to the non-poor households. Table 3 depicts the fact that even the lowest absolute cost incurred by the poor group than non-poor groups, the total cost shared by the poor households exceed (22.0 percent per household) the benefit received (18.0 percent per household) and hence the poor income households have negative net benefit $(-3)$ with less than one $\mathrm{B} / \mathrm{C}$ ratio $(0.81)$. The reasons behind to be negative net benefit and the negative $\mathrm{B} / \mathrm{C}$ ratio for poorer households are: a) high share 
of transaction costs, b) lower opportunity costs of labour, c) failure to internalize the benefit from $\mathrm{CF}, \mathrm{d})$ use low value products from $\mathrm{CF}$ and moreover and e) dominance of non-exclusive characteristics of benefit-cost sharing of a common property forest resource management regime.

Table 3 shows that rich households have highest gross cost and benefits from CF followed by middle-income households. The reasons of high gross cost and benefits of rich income group are: a) harvesting and use more and almost all types of forest products, b) harvesting and use of high value forest products such as timber green fodder and grass from $\mathrm{CF}, \mathrm{c}$ ) domination in forest management and utilization activities and d) high purchasing power for bidding the products if set out for auction sale.

Households from middle-income groups have equal gross cost and benefits from CF and hence they obtained zero net benefits and zero benefit cost ratio apparently to be no net loss and no net gain situation from forestry activities. The likely causes for this are: a) high opportunity cost of labour, b) harvesting highest number of low value bedding materials for agriculture and livestock and c) harvesting small quantity of high value forest products such as timber. It can be said that this group is able to internalize the externalities by equalize the benefit from and cost of CF. Zero net benefit and zero b/c ratio of middle-income group are the evidence of this fact. However, the middleincome group has higher gross benefit and cost compared to poor income group even to be zero net benefit and zero $\mathrm{b} / \mathrm{c}$ ratio.

\section{Externality Analysis}

An externality analysis of CF use and management can be examined based on per household monetary value of benefits (income) of different forest products and the management costs of community forests as derived above for the three income groups of households. The benefits from and gross costs of CF use and management are said to be internalized if each of the income group of households is made to bear them in full. The summary statistics of Table 2 demonstrates the household level variation of benefits accrued in relation with gross costs incurred by different income groups of households within and between the income groups. For example, three income groups of households i.e. rich, middle and poor households are getting per household average gross monetary value of benefit by 45.0 percent, 37.0 percent and 18.0 percent respectively while they are sharing per household average gross costs by 41.0 percent, 37.0 percent and 22.0 percent respectively.
Comparative data of the benefits accrued and average gross cost incurred by different income groups of households indicates that the rich income groups of households have more involvement in the overall forestry activities and they have high gross value per household than the middle income groups of households. Contrary to this, poor income group of households have low average gross cost per household than the non-poor households having lowest average gross value per household than the per household total gross cost incurred. In summary, the poor income group of households has more gross cost per household than gross value/benefit per household and the non-poor groups of households have high per household gross value/benefit than per household gross cost. Thus, the poor income groups of households have completely failed to internalize the benefit from $\mathrm{CF}$ as per the total gross cost incurred by them. Due to non-exclusive characteristics of management of community forest as common property resources, since even a benefit loser, the poor income groups of households must have taken part in overall total gross costs of forest use and management. Thus, rich and the middle income households are getting more benefit and paying less per household total gross cost without providing any compensation to the poor income groups.

Thus, the externality effect of CF in terms of positive externality (benefits) and the negative externality (gross cost transaction costs) is positively related to the poor and non- poor income groups of households i.e. low benefit and cost for poor income group and high benefits and costs for higher income groups of households. According to table 8.10, substantial variation of per household gross value/ benefit sharing from $\mathrm{CF}$ among the income groups indicates that equity outcome of CF management seems likely to be inefficient. Because out of three income groups, the poor group of households are getting less benefits than the costs and hence they are being unable to internalize both the positive and negative externality of CF use management in terms of gross benefits and gross cost. While rich and middle income groups of households are disproportionately getting more benefits than the costs and hence they are being able to internalize the benefit from CF by externalized the gross cost on poor income group of households. Enjoying the benefits according to burdening the costs is the central notion of internalization of positive and negative externality from the management of common property resources. If equity outcome of CF management would be in place, nobody could externalize the costs (negative externality) on others 
to gain disproportionate benefits (positive externality) from $C F$ as common property resources. Thus, it is concluded that in case of benefit accrued and gross cost incurred of CF use and management by different income groups of households, the externalities of CF has not created equity efficiencies between the income groups of households in the study area.

\section{CONCLUSIONS}

Although, the environmental value by vegetation cover (bio-physical condition) of forest resources were found remarkably enhanced since the forest resource management regime shifted from state to local community participatory management, however, due to the lack of relationship about different linkages between rural poverty and environmental/natural resources, equitable distribution of forests resources within the rural community especially across the disadvantaged and marginalized groups of poor people has not been clearly demonstrated. The finding of benefitcost analysis showed that the average percentage differences of household level benefit and cost i.e. net benefits of CF was positive for the rich (45.0 $41.0=4.0)$, zero for the middle-income $(37.0-37.0=$ 0 ) and negative for the poor income group of households $(22.0-18.0=-4.0)$ respectively. Consequently, the benefit-cost ratio $(\mathrm{B} / \mathrm{C})$ for the rich households was more than one (1.09), middleincome households equal to one (1.0) and the poor income household less than one $(-0.81)$.

As per the results of externality analysis the poor income households failed to internalize the benefit from CF as per the total gross cost incurred by them. The middle incomes households were able to internalize by equalize both of gross benefit and the gross cost. The rich income households were able to externalize the gross cost on the poor income households to gain disproportionate net benefits from CF. Thus, it is concluded that in case of benefit accrued (positive externality) and gross cost incurred (negative externality) of CF use and management by different income groups of forest users' households, the externalities of CF had not created equity efficiencies between the income groups of households in the study area.

Thus, conclusion of externality analysis raises the concern of whether conservation-oriented measures that promote regulated systems of forest management in Nepal undermined social goals such as equitable distribution of benefits and costs among the forest dependent households. It is reasonable to require that policies aimed at allocating forest resources should not eschew equity concerns altogether. Finally, number of recommendations could provide to improve community forest management and equity in benefit-cost distribution in Nepal.

\section{REFERENCES}

Adhikari, B. 2003. Property rights and natural resources: Socio-economic heterogeneity and distributional implications of common property resource management. Kathmandu: South Asian Network for Development and Environmental Economics (SANDEE), Working Paper No.1-03.

Bhattarai, B. \& Ojha, H. R. 2001. Distributional impact of community forest. Kathmandu: Forest Action Research Series No.2000/01.

Dahal, M. R. 2006. Externalities and distributional implications of community forest management: A case of Arun River Valley. Unpublished Ph.D. Dissertation, Tribhuvan University, Kathmandu, Nepal.

Godoy, R., Lubowski, R., \& Markandya, A. 1993. A method for economic valuation of non-timber tropical forest products. Economic Botany, 47: 220-233.

Gunatilake, H.M. 1998. The role of rural development in protecting tropical rainforests: Evidence from Sri Lanka. Journal of Environmental Management, 53: 273-292.

Fox, J.M. 1983. Managing Public Land in a Subsistence Economy: The Perspective from a Nepali Village. Unpublished doctoral dissertation, University of Wisconsin-Madison.

Richards, M., Kanel, K., Maharjan, M., \& Davies, J. 1999. Towards the participatory economic analysis by forest user groups in Nepal. London: Oversees Development International, Portland House.

Todaro, M.P., \& Smith, S. C. 2004. Economic development. Eighth Edition, Pearson Education, Singapore, Last Indian Reprint 2004.

Varughese, G. and K. Kanel 2000. Quantifying the benefit of community forestry in Nepal Towards development of a participatory methodology of economic valuation. Paper presented at the Eighth Biennial Meetings of the International Association for the Study of Common Property at Indiana University, Bloomington, Indiana USA (30 May-4 June 2000). 
M.R. Dahal..... EXTERNALITY ANALYSIS /69

Annex Table A: Gross Benefits per Household of CF (In Nepalese Rupees).

\begin{tabular}{|c|c|c|c|c|c|c|c|c|c|c|c|}
\hline \multirow[b]{3}{*}{ CFUGs } & \multicolumn{3}{|c|}{ Rich } & \multicolumn{3}{|c|}{ Medium } & \multicolumn{3}{|c|}{ Poor } & \multicolumn{2}{|r|}{ Total } \\
\hline & \multicolumn{3}{|c|}{ Gross income } & \multicolumn{3}{|c|}{ Gross income } & \multicolumn{3}{|c|}{ Gross income } & & \\
\hline & $\mathrm{N}^{*}$ & Rs. & $\%$ & $\mathrm{~N}^{*}$ & Rs. & $\%$ & $\mathrm{~N}^{*}$ & Rs. & $\%$ & $\mathrm{~N}^{*}$ & Total Average \\
\hline Panchakanya & 6 & 7596 & 43 & 6 & 6641 & 37 & 7 & 3599 & 20 & 19 & 5822 \\
\hline Dakshinkali & 5 & 6862 & 44 & 4 & 6089 & 39 & 8 & 2585 & 27 & 17 & 4667 \\
\hline Arunganga & 10 & 8053 & 46 & 9 & 6121 & 35 & 12 & 3500 & 20 & 31 & 5730 \\
\hline Oiputang & 5 & 6605 & 36 & 7 & 7119 & 39 & 12 & 4424 & 24 & 24 & 5665 \\
\hline Jalasinghadevi & 7 & 7067 & 40 & 5 & 6380 & 37 & 3 & 4030 & 23 & 15 & 6230 \\
\hline Khorsane & 4 & 7515 & 44 & 4 & 5937 & 35 & 5 & 3672 & 21 & 13 & 5551 \\
\hline Shivaratrighat & 13 & 6111 & 45 & 4 & 4915 & 36 & 11 & 2630 & 19 & 28 & 4573 \\
\hline Barnebelayate & 3 & 6187 & 45 & 17 & 5125 & 37 & 6 & 2378 & 17 & 26 & 4614 \\
\hline Tarebhir & 8 & 7174 & 46 & 19 & 5913 & 38 & 12 & 2478 & 16 & 30 & 4857 \\
\hline Salleri & 9 & 10026 & 49 & 17 & 7389 & 36 & 23 & 2903 & 14 & 49 & 5768 \\
\hline Salghari & 5 & 13688 & 52 & 8 & 6935 & 26 & 6 & 5841 & 22 & 19 & 8367 \\
\hline Arunodaya & 8 & 7050 & 45 & 6 & 5638 & 36 & 5 & 2922 & 19 & 19 & 5518 \\
\hline Rupadahari & 3 & 6203 & 39 & 10 & 6733 & 42 & 6 & 3173 & 20 & 19 & 5525 \\
\hline Chhyangripasini & 8 & 7725 & 54 & 7 & 6622 & 46 & 0 & 0 & 0 & 15 & 7210 \\
\hline Chabbar & 4 & 7265 & 41 & 13 & 6738 & 38 & 12 & 3539 & 20 & 29 & 5487 \\
\hline Bancharedanda & 13 & 8565 & 47 & 16 & 6739 & 37 & 17 & 2764 & 15 & 47 & 5786 \\
\hline Grand Total & 111 & 7786 & 45 & 143 & 6397 & 37 & 145 & 3236 & 19 & 399 & 5635 \\
\hline
\end{tabular}

Annex Table B: Gross Cost per Household of Use and Management (In Nepalese Rupees)

\begin{tabular}{|c|c|c|c|c|c|c|c|c|c|c|c|}
\hline \multirow[b]{2}{*}{ CFUGs } & \multirow[b]{2}{*}{$\mathrm{N}^{*}$} & \multicolumn{2}{|c|}{ Rich } & \multicolumn{3}{|c|}{ Medium } & \multicolumn{3}{|c|}{ Poor } & \multicolumn{2}{|c|}{ Total } \\
\hline & & Rs. & Percent & $\mathrm{N}^{*}$ & Rs. & Percent & $\mathrm{N}^{*}$ & Rs. & Percent & $\mathrm{N}^{*}$ & Rs. \\
\hline Panchakanya & 6 & 4736 & 39 & 6 & 4439 & 37 & 7 & 2867 & 24 & 19 & 12042 \\
\hline Dakshinkali & 5 & 4586 & 41 & 4 & 4084 & 36 & 8 & 2553 & 23 & 17 & 11223 \\
\hline Arunganga & 10 & 5589 & 44 & 9 & 4362 & 34 & 12 & 2888 & 22 & 31 & 12839 \\
\hline Oiputang & 5 & 4035 & 33 & 7 & 4743 & 39 & 12 & 3314 & 27 & 24 & 12092 \\
\hline Jalasinghadevi & 7 & 5573 & 40 & 5 & 5166 & 37 & 3 & 3210 & 23 & 15 & 13950 \\
\hline Khorsane & 4 & 4271 & 37 & 4 & 4221 & 36 & 5 & 3173 & 27 & 13 & 11665 \\
\hline Shivaratrighat & 13 & 4615 & 46 & 4 & 3412 & 34 & 11 & 1925 & 19 & 28 & 9951 \\
\hline Barnebelayate & 3 & 5102 & 41 & 17 & 4514 & 37 & 6 & 2695 & 22 & 26 & 12311 \\
\hline Tarebhir & 8 & 5169 & 44 & 19 & 4301 & 37 & 12 & 2215 & 19 & 30 & 11684 \\
\hline Salleri & 9 & 5183 & 43 & 17 & 4424 & 37 & 23 & 2489 & 21 & 49 & 12096 \\
\hline Salghari & 5 & 5856 & 44 & 8 & 4590 & 35 & 6 & 2809 & 21 & 19 & 13254 \\
\hline Arunodaya & 8 & 5274 & 43 & 6 & 4008 & 33 & 5 & 3008 & 24 & 19 & 12290 \\
\hline Rupadahari & 3 & 3832 & 36 & 10 & 4248 & 40 & 6 & 2460 & 23 & 19 & 10540 \\
\hline Chhyangripasini & 8 & 4810 & 50 & 7 & 4752 & 50 & 0 & 0 & 0 & 15 & 9562 \\
\hline Chabbar & 4 & 5175 & 41 & 13 & 4504 & 36 & 12 & 2963 & 23 & 29 & 12641 \\
\hline Bancharedanda & 13 & 5230 & 42 & 16 & 4827 & 38 & 17 & 2543 & 20 & 47 & 12600 \\
\hline Grand Total & 111 & 5017 & 41 & 143 & 4469 & 37 & 145 & 2669 & 22 & 399 & 12155 \\
\hline
\end{tabular}

Source: Field Survey, 2003. * Number of households 